\title{
THE DISTRIBUTION OF SPERMATOZOA AND LEUCOCYTES IN THE FEMALE GENITAL TRACT IN GOATS AND CATTLE
}

\author{
P. E. MATTNER* \\ Physiology Department, National Institute for Research in Dairying, \\ Shinfield, Reading
}

(Received 25th October 1967, accepted 4th March 1968)

\begin{abstract}
Summary. Quantitative studies were made of the distribution of spermatozoa and leucocytes in the female genital tract of mated goats and cows near the time of ovulation and of the leucocytes in the genital tract of unmated goat does at a similar time. In both species, the cervix appeared to act as a reservoir for spermatozoa. Spermatozoa were not uniformly distributed through the lumen of the cervix but tended to be aggregated in the vicinity of the cervical mucosa.

The presence of spermatozoa in the genital tract resulted in an increased number of leucocytes in the lumen of the uterus and cervix. In the cervix, the majority of the leucocytes occurred in the central mass of the mucus, this being consistent with the main invasion of the cervical mucus by the leucocytes taking place from the uterus. The resulting separation of spermatozoa and leucocytes in the cervix is probably an important factor in the survival of an adequate population of spermatozoa in the cervix of ruminants after mating.
\end{abstract}

\section{INTRODUCTION}

Although the distribution of spermatozoa in the genital tract of mated ewes has been studied quantitatively (Warbritton, McKenzie, Berliner \& Andrews, 1937; Braden \& Austin, 1954; Mattner \& Braden, 1963; Mattner, 1963), similar studies have not been made with cows or goat does.

In small laboratory animals, the presence of spermatozoa in the uterus does not materially influence the infiltration of leucocytes into the lumen of the uterus until after the end of oestrus (McDonald, Black, McNutt \& Casida, 1952; Austin, 1957; Yanagimachi \& Chang, 1963). Nevertheless, Howe \& Black (1963) found that large numbers of leucocytes invaded the vagina, and ingested spermatozoa, within 4 to $8 \mathrm{hr}$ after vaginal insemination in calves. However, detailed or quantitative studies on the distribution of leucocytes in the lumen of the female genital tract and the leucocytic response to the presence of spermatozoa in the tract have not been made in any species of ruminant.

* Present address: Division of Animal Physiology, C.S.I.R.O., Ian Clunies Ross Animal Research Laboratory, Prospect, New South Wales, Australia. 
The present studies were undertaken to provide information on these subjects.

\section{Animals}

\section{MATERIALS AND METHODS}

Twelve parous Saanen goat does, $3 \frac{1}{2}$ to 6 years old, were stratified according to age and individuals from each age group were allotted at random into two groups (A and B). Does in Group A were mated once with a fertile buck as soon as possible after the observed onset of oestrus and were killed $24 \mathrm{hr}$ later. Does in Group B were not mated and were killed approximately $24 \mathrm{hr}$ after the observed onset of oestrus.

Five parous Friesian cows, 3 to 5 years old, were each mated twice, within $15 \mathrm{~min}$, with a fertile bull during early oestrus and were killed 19 to $22 \mathrm{hr}$ later.

Determination of numbers of spermatozoa and leucocytes in the lumen of genital tracts

Goat does were killed by intra-cardiac injection with $20 \mathrm{ml}$ of $6 \%$ pentobarbitone solution and, within 2 to $4 \mathrm{~min}$ of this procedure, ligatures were applied at the base of the Fallopian tubes, the utero-cervical junction and the caudal end of the cervix. The genital tracts were immediately removed, divided and flushed by the method of Mattner \& Braden (1963) except that each uterine horn and cervix was flushed twice using separate 5-ml quantities of warm saline. Mucus present in cervical flushings was disintegrated with a few drops of neutralized hypochlorite solution. The numbers of spermatozoa and leucocytes in the flushings were determined by methods previously outlined for determination of spermatozoan numbers (Mattner \& Braden, 1963).

The methods used with cattle were similar, except that cows were killed with a captive-bolt gun and ligation of the genital tracts was delayed until approximately $10 \mathrm{~min}$ after death. Further, each uterine horn and cervix was flushed with two separate $15-\mathrm{ml}$ quantities of saline.

After being flushed, the cervices were fixed, sectioned and stained by methods outlined below. Spermatozoan heads and nuclei of polymorphonuclear leucocytes (polymorphs) present in the lumen of the cervix and cervical glands were counted in sixteen complete cross-sections cut at $5 \mu$ thickness and taken at approximately equal intervals along the length of the cervix. The counts were corrected for error arising out of the interaction between thickness of section and nuclear size by applying Abercrombie's formula (Abercrombie, 1946). The bias for counts of spermatozoan heads and polymorph nuclei in sections of $5 \mu$ was $+120 \%$ and $+80 \%$ respectively.

\section{Estimation of numbers of leucocytes in endometrial stroma of cervices and uteri}

Immediately after being flushed, the whole cervices and uteri of the goats were fixed in formol saline. In the case of cattle, the cervix was also fixed whole, but only specimens of the uterine horns obtained at equal intervals along the horns were taken for fixation. Cervices were divided into four portions (blocks) of equal length, uterine horns into six such blocks, after the length of the fixed organ had been recorded. Four complete cross-sections cut at $5 \mu$ 
thickness were taken at approximately equal intervals along each block. Sections were stained by the Lillie \& Pasternack azure-eosinate method (Lillie, 1954) with the substitution of toluidine blue for the azure A used in the original method. The area of endometrial stroma in each section was determined, using tracings of the projected image of the section and a disc planimeter. For counting of polymorphs in sections of the endometrial stroma, a thin, circular piece of glass, marked with a square whose sides corresponded with $150 \mu$ at 512 magnifications, was inserted into one eye piece of the microscope. This square was divided by two further lines into quarters.

Uterine counts. Polymorphs were not uniformly distributed throughout the endometrial stroma and it was necessary to sample a section by examining the complete width of stroma. One side of the square was aligned against the basement membrane of the mucosa and polymorphs within the area were counted. The square was then moved in successive stages of $150 \mu$ outward from the mucosa until the myometrium was reached. The procedure was repeated for twenty positions (sites) taken at intervals around the perimeter of the mucosa.

Cervical counts. The polymorphs were randomly distributed through the endometrial stroma. Counts were made with the counting square placed in twenty positions (sites) taken at random. Within the villi of the cervical epithelium, the endometrial stroma was frequently less than $150 \mu$ in width. In such an area, the combined polymorph count for four of the quartersquares taken along the villus constituted a count for one site.

The protocol given for sampling uterine and cervical tissue was adopted following a pilot study with analysis of variance to determine the numbers of blocks, sections per block and sites per section necessary to ensure representative sampling.

The number of polymorphs in the endometrial stroma of an organ was obtained by totalling the numbers in each block. The number of polymorphs $(\mathcal{N})$ in each block was estimated as follows:

$$
\mathcal{N}=\frac{P \times S \times L}{A \times T}
$$

where $P=$ mean no. polymorphs/counting square, $S=$ mean area of stroma, $L=$ length of block, $A=$ area of counting square, and $T=$ thickness of section.

\section{Treatment of data}

The values obtained were transformed on the $\log _{10}$ scale so as to give homogeneous variability and the data were analysed by analysis of variance.

\section{RESULTS}

At slaughter, ovulation of at least one egg had occurred in four of the mated goats. The ovaries in the remaining does contained one or more large follicles. Ovulation had occurred shortly before death in three cows, while an ovary of each of the other two animals contained a large follicle. 
Distribution of spermatozoa and leucocytes in the lumen of the genital tracts

The mean $\log _{10}$ numbers (with s.E. and antilog) of spermatozoa and of leucocytes found in the cervix, uterus and Fallopian tubes of mated goat does and cows are shown in Table 1.

In each animal, the number of spermatozoa in the cervix greatly exceeded the total number of spermatozoa in the uterus and Fallopian tubes. Further, the proportions of non-motile and tail-less cells were lower in spermatozoa flushed from the cervix than in those flushed from the uterus or the Fallopian tubes in both goat does and cows (see Table 1).

TABLE 1

DISTRIBUTION OF SPERMATOZOA AND LUMINAL LEUGOGYTES IN THE GENITAL TRACT IN GOAT DOES AND GOWS

\begin{tabular}{|c|c|c|c|c|c|}
\hline $\begin{array}{c}\text { Species, } \\
\text { treatment and } \\
\text { no. of animals }\end{array}$ & $\begin{array}{l}\text { Division } \\
\text { of tract }\end{array}$ & $\underset{\left.\quad \text { Mean } \log _{10} \pm \text { antilog }\right)}{\text { S.E. }}$ & $\underset{\left.\quad \text { Mean } \log _{10} \pm \text { antilog }\right)}{\text { S.E. }}$ & $\begin{array}{l}\% \text { motile } \\
\pm S . E .\end{array}$ & $\begin{array}{c}\% \text { tail-less } \\
\pm S . E .\end{array}$ \\
\hline \multirow[t]{3}{*}{$\begin{array}{l}\text { Goats, mated } \\
\quad(6)\end{array}$} & Cervix & $\begin{array}{c}5 \cdot 498 * * \pm 0 \cdot 085 \\
(315,000)\end{array}$ & $\begin{array}{c}6 \cdot 362 \pm 0 \cdot 104 \\
(2,300,000)\end{array}$ & & $8 \pm 2 \dagger$ \\
\hline & Uterus & $\begin{array}{c}5 \cdot 717^{*} \pm 0 \cdot 085 \\
(521,000)\end{array}$ & $\begin{array}{c}5 \cdot 170 \pm 0 \cdot 201 \\
(148,000)\end{array}$ & $49 \pm 3$ & $23 \pm 3$ \\
\hline & $\begin{array}{l}\text { Fallopian } \\
\text { tubes }\end{array}$ & $\begin{array}{c}2 \cdot 668 \pm 0 \cdot 154 \\
(470)\end{array}$ & $\begin{array}{c}3 \cdot 889 \pm 0 \cdot 218 \\
(7,740)\end{array}$ & $45 \pm 3$ & $30 \pm 4$ \\
\hline \multirow[t]{3}{*}{$\begin{array}{l}\text { Goats, unmated } \\
\quad(6)\end{array}$} & Cervix & $\begin{array}{c}4 \cdot 750 * * \pm 0 \cdot 139 \\
(56,000)\end{array}$ & - & - & - \\
\hline & Uterus & $\begin{array}{c}5 \cdot 210 \pm 0 \cdot 109 \\
(158,000)\end{array}$ & - & - & - \\
\hline & $\begin{array}{l}\text { Fallopian } \\
\text { tubes }\end{array}$ & $\underset{(320)}{2 \cdot 511 \pm 0 \cdot 143}$ & - & - & - \\
\hline \multirow[t]{3}{*}{$\begin{array}{l}\text { Cows, mated } \\
(5)\end{array}$} & Cervix & $\begin{array}{c}5 \cdot 803 \pm 0 \cdot 081 \\
(635,000)\end{array}$ & $\begin{array}{c}6 \cdot 616 \pm 0 \cdot 089 \\
(4,130,000)\end{array}$ & $64 \pm 3$ & $11 \pm 2$ \\
\hline & Uterus & $\begin{array}{c}6 \cdot 149 \pm 0 \cdot 091 \\
(1,409,000)\end{array}$ & $\begin{array}{c}5.937 \pm 0.085 \\
(850,000)\end{array}$ & $52 \pm 3$ & $28 \pm 3$ \\
\hline & $\begin{array}{l}\text { Fallopian } \\
\text { tubes }\end{array}$ & $\begin{array}{c}2 \cdot 899 \pm 0 \cdot 122 \\
(790)\end{array}$ & $\begin{array}{c}3 \cdot 858 \pm 0 \cdot 139 \\
(7,210)\end{array}$ & $38 \pm 4$ & $37 \pm 4$ \\
\hline
\end{tabular}

Leucocytes, some containing ingested spermatozoa, were present in all divisions of the genital tract in goats and cows (Table 1) and in all animals the number in the uterus exceeded the number in the cervix. No obvious correlation occurred between the numbers of spermatozoa and leucocytes in either the uterus or the cervix in either species. Correlations between the number of leucocytes in the uterus and the number of leucocytes in the cervix for separate groups of animals failed to reach statistical significance. However, when the data from all goats (mated and unmated) were combined, a significant correlation was found between the numbers of leucocytes in the two organs $(r=0.683, n=12,0.01<P<0.05)$. The correlation was also significant $(r=0.646, n=11,0.01<P<0.05)$ when data from mated goats and cows were combined. 
The distribution of leucocytes in the genital tracts was similar in the mated and unmated does, but greater numbers of luminal leucocytes were found in the uteri and cervices in mated than in unmated animals. Using analysis of variance, the difference between the mean $\log _{10}$ numbers of leucocytes in the uteri of mated and unmated goats was significant $(P<0.05)$ and the difference between the mean $\log _{10}$ numbers in the cervices was also significant $(P<0 \cdot 01)$.

Examination of stained smears prepared from flushings from the genital tracts showed that more than $95 \%$ of the leucocytes in the cervix, the uterus and the Fallopian tubes of goats and cows were polymorphonuclear types. The remainder were mainly monocytes with some eosinophils and lymphocytes.

Histological examination of the previously flushed cervices showed that, in both goats and cows, strands of mucus remained in many of the crypts between the villi and the simple cervical glands. Although aggregations of spermatozoa occurred at these sites, particularly within the crypts, very few leucocytes were present (see Plate 1). Counts made on the flushings from the cervices and in sections of the flushed cervices showed that, while 51 (S.E. 4 ) $\%$ and 43 (S.E. 4 ) \%, respectively, of the total number of spermatozoa were recovered in the flushings in goats and cows, the corresponding percentages of leucocytes recovered were 96 (s.e. 1) and 92 (s.e. 2), respectively. Further, the mean ratios for the number of spermatozoa: the number of leucocytes in sections and in flushings from the cervix were $164: 1$ (range, $40: 1$ to $520: 1$ ) and $5: 1$ (range, $1: 1$ to $12: 1$ ), respectively, for goats and were $57: 1$ (range, 35:1 to 93:1) and 4:1 (range, $1: 1$ to $8: 1$ ), respectively, for cows.

An assessment of the proportion of mucus removed from the cervix by the flushing procedure was obtained using the cervices of two goats and two cows killed during late oestrus. Each cervix was flushed as described previously and the volume of mucus recovered was measured. Dilute sodium hypochlorite solution was used to break down the mucus remaining in the cervix and the increased volume of the recovered liquid represented the volume of the mucus previously retained. It appeared that, in both species, approximately ninetenths of the mucus in the cervix was removed by the flushing procedure. As judged from Alcian-blue stained sections of cervices from the mated experimental goats and unflushed cervices from two other mated goats, such assessments were reasonable. The flushing not only removed almost all of the mucus from the main part of the lumen but also the spermatozoa-laden mucus from some of the crypts between the villi.

Distribution of polymorphonuclear leucocytes in the endometrial stroma of the cervix and uterus

Since approximately $95 \%$ of the leucocytes in the lumen of the genital tract were polymorphonuclear leucocytes (polymorphs), account was taken of this type of cell only.

The distribution of polymorphs in the endometrial stroma of the cervix and uterus was similar in the mated and unmated goats and mated cows.

Numerous polymorphs were present in the epithelial stroma of the uterus, immediately beneath the mucosal layer, in goats and cows. They were frequently seen between the mucosal cells and there was a tendency for aggrega- 
tions to occur in the immediate vicinity of the uterine glands which sometimes contained large numbers of polymorphs. Of the total number of polymorphs in the endometrial stroma of goats and cows, 92 (s.E. 2) \% and 87 (s.E. 2)\%, respectively, lay within $150 \mu$ of the mucosal layer. For mated goats, unmated goats and cows (mated), the mean numbers ( \pm s.e.) of polymorphs per $150 \mu$ square of tissue in this area were $11 \cdot 11 \pm 4 \cdot 64,7 \cdot 61 \pm 2 \cdot 42$ and $15 \cdot 93 \pm 3 \cdot 12$, respectively.

In the cervix, few polymorphs were found in the endometrial stroma and there was no definite pattern in their distribution within the layer. Polymorphs were rarely seen in close approximation to the basement membrane of the mucosa and they did not tend to be grouped in the vicinity of the cervical glands. For mated and unmated goats and mated cows, the mean numbers ( \pm s.E.) of polymorphs per $150 \mu$ square of endometrial stroma in the cervix were $0.17 \pm 0.03,0.14 \pm 0.02$ and $0.12 \pm 0.02$, respectively.

TABLE 2

COMPARISON OF THE NUMBERS OF POLYMORPHONUCLEAR LEUCOCYTES IN THE ENDOMETRIAL STROMA OF THE CERVICES AND UTERI OF MATED AND UNMATED GOAT DOES

\begin{tabular}{l|cc|c}
\hline \multirow{1}{*}{$\begin{array}{c}\text { Treatment } \\
\text { of does }\end{array}$} & \multicolumn{2}{|c|}{$\begin{array}{c}\text { Mean } \log _{10} \text { no. polymorphs } \pm \text { S.E. } \\
\text { Cervitog }) \text { in }\end{array}$} & $\begin{array}{c}\text { Mean difference } \\
\text { (uterus-cervix) }\end{array}$ \\
\hline Mated & $5 \cdot 722 \pm 0.087$ & $7 \cdot 774 \pm 0.138$ & $2 \cdot 052 * * *$ \\
Unmated & $(530,000)$ & $(59,400,000)$ & \\
Mean difference & $5 \cdot 619 \pm 0.081$ & $7 \cdot 688 \pm 0.086$ & $2 \cdot 069^{* * *}$ \\
& $(420,000)$ & $(48,870,000)$ & \\
\hline
\end{tabular}

Means based on six animals.

$\left.\begin{array}{l}\text { s.e. of difference between means, Mated-unmated }=0.155 \\ \text { Uterus-cervix }=0.144\end{array}\right\}$ d.f. $=10$.

*** Difference significant, $P<0.001$.

N.s. Difference not significant, $P>0.05$.

The mean $\log _{10}$ numbers of polymorphs in the endometrial stroma of the cervices and uteri of mated and unmated goats are shown and compared in Table 2. Variation between animals in the number of polymorphs in either the uterine or the cervical endometrial stroma was large but in every animal the number of polymorphs in the cervical stroma was extremely small compared with the number in the uterine stroma. In the mated animals, the numbers of polymorphs in the endometrial stroma in the uterus and in the cervix were approximately $30 \%$ and $20 \%$ higher, respectively, than the number in the corresponding organs in unmated animals, but the differences between the mean $\log _{10}$ numbers were not significant.

With mated animals, there was no obvious relationship between the number of polymorphs in the uterine endometrial stroma and the number of spermatozoa in either the uterus or the cervix. Nor was there any obvious relationship between the number of polymorphs in the cervical endometrial stroma and either the number of spermatozoa or the number of polymorphs in the lumen 


\section{PLATE 1}

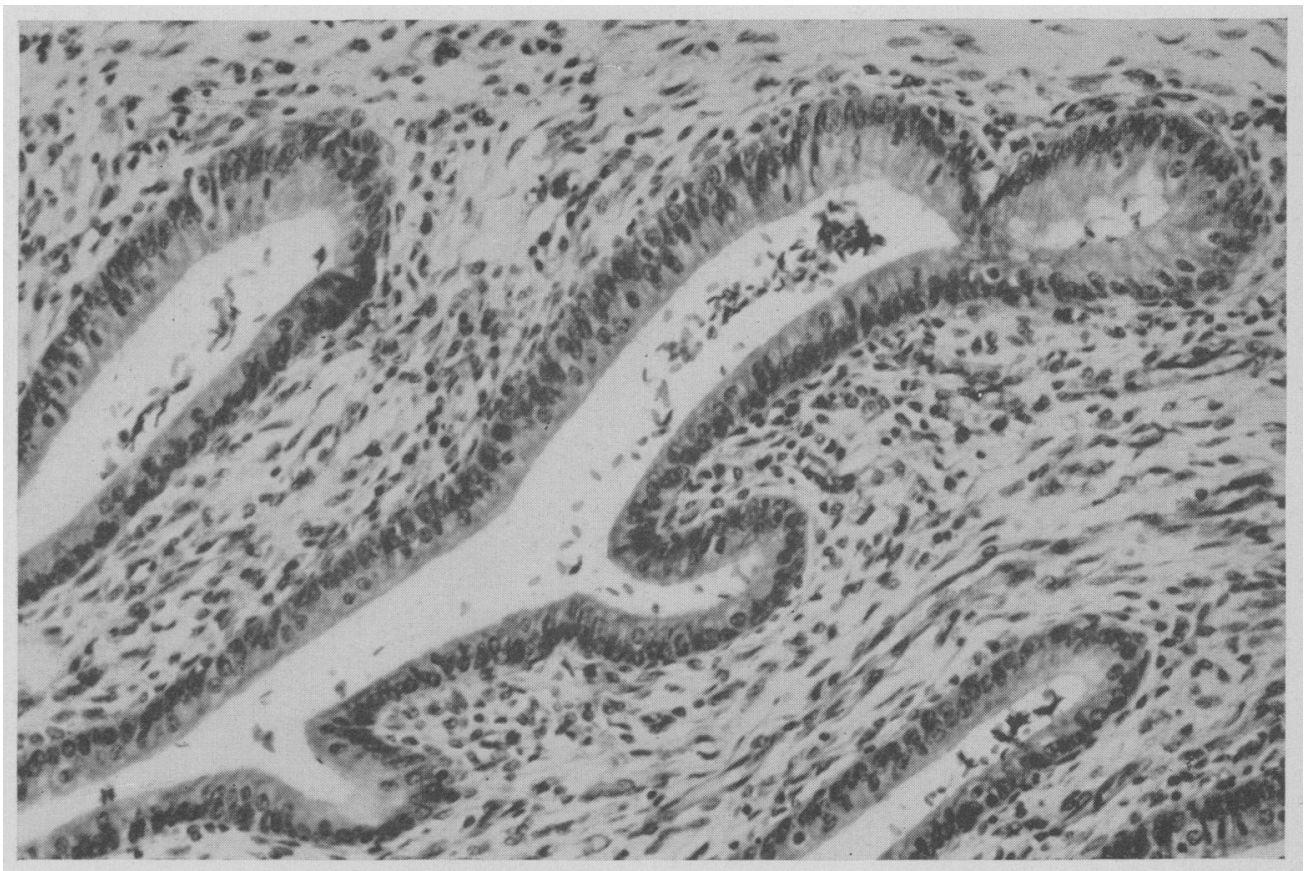

Section of a caprine cervix after flushing showing aggrcgations of spermatozoa in the base of crypts between villi. Almost complete absence of leucocytes in the lumen. Fixed in formol saline, stained with haematoxylin and $\operatorname{cosin} . \times 150$. 
of the cervix. However, when the data from mated and unmated goats were combined, a significant correlation was found between the number of polymorphs in the endometrial stroma of the uterus and the number of polymorphs in the lumen of that organ $(r=0.701, n=12,0.01<P<0.05)$.

\section{DISCUSSION}

In the present study, a greater number of spermatozoa was found in the cervix than in the uterus and Fallopian tubes in both cows and goats; the majority of the spermatozoa recovered from the cervices at 18 to $22 \mathrm{hr}$ after mating in cows and at $24 \mathrm{hr}$ after mating in goats were motile, and a smaller proportion of obviously damaged spermatozoa were recovered from the cervix than were recovered from the uterus or the Fallopian tubes in either species. These findings in cows, together with observations by Kirillov (1937), Beshlebnov (1938) and Sergin, Kuznecov, Kozlova \& Nesmejanova (1940), which indicate that spermatozoa survive longer in the cervix than elsewhere in the genital tract of the cow, suggest that, similar to the situation in ewes (Quinlan, Mare \& Roux, 1932, 1933; Mattner, 1963), a large reserve of viable spermatozoa persists in the cervix in cows after mating. It would also appear from the present results that a similar reserve is maintained in the cervix in the goat doe.

Although approximately $90 \%$ of the cervical mucus was removed by the flushing procedure, only about $50 \%$ of the spermatozoa present in the cervices were removed by the same procedure. This suggests that the spermatozoa in the cervices in goats and cows are not uniformly distributed within the lumen but tend to be aggregated at or in the vicinity of the mucosa. The tendency may, in fact, be greater than was demonstrated as the flushing procedure evidently removed the mucus from many of the crypts between the villi, and spermatozoa in this material would also have been removed and counted in the flushings. As outlined previously (Mattner, 1966a), the aggregation of spermatozoa near the mucosa could occur because of anisotropy of the mucus leading to persistent alignment of spermatozoa parallel to the molecular strands of the mucoid in such mucus.

On the other hand, the distribution of the polymorphs in the lumen of the cervix was the reverse of that for spermatozoa; the great majority were within the central mass of mucus in the lumen. Such a distribution could be expected to occur if the main invasion of the cervical lumen by polymorphs took place from the lumen of the uterus rather than from the cervical mucosa. The greatest amount of flow as mucus drains from the cervix into the vagina would occur in the central rather than in the peripheral region, and thus there should be a tendency for polymorphs entering from the lumen of the uterus to be carried passively in the central mass of the cervical mucus.

Other findings in the present study support this contention. Compared with that of the uterus, the endometrial stroma of the cervix was only sparsely infiltrated with polymorphs in both goats and cows. Further, there was no obvious relationship between the number of polymorphs in the lumen of the cervix and the number in the endometrial stroma of the cervix. On the other hand, the number of polymorphs in the lumen of the cervix was related to the 
number present in the lumen of the uterus and was lower than the latter in each animal examined.

Thus the aggregation of spermatozoa within the crypts of the cervix or in close proximity to the cervical mucosa would limit the amount of contact occurring between the spermatozoan reserve and the polymorphs entering the cervix from the lumen of the uterus. It is suggested that this spatial separation of the two types of cells plays an important part in the survival of an adequate population of spermatozoa in the cervix in ruminants. As seen with goat does, the invasion of the genital tract by spermatozoa resulted in an increased number of polymorphs in the lumen of the uterus and cervix, while it has been found in vitro that apparently normal spermatozoa swimming vigorously through cervico-vaginal mucus of ruminants are frequently engulfed when they, as a result of their own movement, make contact with polymorphs in the mucus (Mattner, 1966b).

\section{ACKNOWLEDGMENTS}

I wish to thank Mrs J. Rose for skilled technical assistance, Mr A. Turvey for preparation of histological material, and Mr D. R. Westgarth and Mr M. R. Jones for advice and statistical analyses. I am also indebted to Dr P. G. Shaw of North Wyke Experimental Station, Fison's Fertilizers Ltd, for the gift of goats and the A.R.G. Institute for Research into Animal Diseases, Compton, for making cattle available.

This work forms part of a programme financed by the Population Council, The Rockefeller University, New York, whose support is gratefully acknowledged.

\section{REFERENCES}

Abercrombie, M. (1946) Estimation of nuclear populations from microtome sections. Anat. Rec. 94, 239. Austin, C. R. (1957) Fate of spermatozoa in the uterus of the mouse and rat. F. Endocr. 14, 335.

Beshlebnov, A. V. (1938) The optimal time of inseminating cows during oestrus. Problemý Zhivot. 2, 73. Anim. Breed. Abstr. 6, 291 (1938).

Braden, A. W. H. \& Austin, C. R. (1954) The number of sperms about the eggs in mammals and its significance for normal fertilization. Aust. F. biol. Sci. 7, 543.

HowE, G. R. \& BLACK, D. L. (1963) Spermatozoan transport and leucocytic responses in the reproductive tract of calves. F. Reprod. Fert. 6, 305.

Kiriljov, V. S. (1937) New principles of the organizations and techniques of mating cows. Problemy Zhivot. 3, 34. Anim. Breed. Abstr. 5, 278 (1937).

LiLLIE, R. D. (1954) Histopathologic technic and practical histochemistry, p. 119. McGraw-Hill, New York.

McDonald, L. E., Black, W. G., McNutT, S. H. \& Gasida, L. E. (1952) The response of the rabbit uterus to instillation of semen at different phases of the oestrus cycle. Am. F. vet. Res. 13, 419.

Mattner, P. E. (1963) Spermatozoa in the genital tract of the ewe. II. Distribution after coitus. Aust. 7. biol. Sci. 16, 688.

MATtNer, P. E. (1966a) Formation and retention of the spermatozoan reservoir in the cervix of the ruminant. Nature, Lond. 212, 1479.

MatTner, P. E. (1966b) The cervix and its secretion in relation to fertility in ruminants. Ph.D. thesis, University of Reading.

Mattner, P. E. \& BRAden, A. W. H. (1963) Spermatozoa in the genital tract of the ewe. I. Rapidity of transport. Aust. F. biol. Sci. 16, 473.

Quinlan, J., Mare, G.S. \& Roux, L. L. (1932) The viability of the spermatozoa in the genital tract of the Merino ewe, with special reference to its practical application in breeding. 18th Rep. vet. Res. Un. S. Afr., p. 831. 
QuinLAN, J., MARE, G. S. \& Roux, L. L. (1933) A study of the duration of motility of spermatozoa in the different divisions of the reproductive tract of the Merino ewe. Onderstepoort 7. vet. Sci. Anim. Ind. 1, 135.

Sergin, N. P., Kuznecov, V. M., Kozlova, V. M. \& Nesmejanova, T. N. (1940) Physico-chemical conditions of the genital tract of the cow and survival of spermatozoa. Dokl. vses. Akad. sel'.-ikhoz. Nauk, 15, 24. Anim. Breed. Abstr. 9,18 (1941).

Warbrttton, V., MaKenzie, F. F., Berliner, V. \& Andrews, F. N. (1937) Sperm survival in the genital tract of the ewe. Rec. Proc. Am. Soc. Anim. Prod. 30, 142.

Yanagimachi, R. \& Chang, M. G. (1963) Infiltration of leucocytes into the uterine lumen of the golden hamster during the oestrous cycle and following mating. F. Reprod. Fert., 5, 389. 